\title{
Gastric Gastrointestinal Stromal Tumor of Uncertain Malignant Potential
}

National Cancer Institute

\section{Source}

National Cancer Institute. Gastric Gastrointestinal Stromal Tumor of Uncertain Malignant

Potential. NCI Thesaurus. Code C95898.

A gastrointestinal stromal tumor arising from the stomach. It is characterized by a maximum diameter greater than $5 \mathrm{~cm}$ and equal or less than $10 \mathrm{~cm}$ and no more than 5 mitotic figures per 50 high power fields. 